\title{
Dural Tears Associated with Burst Fractures of Lumbar Vertebrae: A Series of Three Cases
}

\author{
Manish Sharma $^{1} \quad$ A. K. Sharma ${ }^{1} \quad$ Maneet Gill $^{1} \quad$ Gaurav Kumar $^{1}$ \\ ${ }^{1}$ Department of Neurosurgery, Army Hospital (Research and \\ Referral), Delhi Cantt, Delhi, India \\ Indian J Neurosurg 2017;6:10-14. \\ Address for correspondence Manish Sharma, MCh, Neurosurgery, \\ Department of Neurosurgery, Army Hospital (Research and Referral), \\ Delhi Cantt., New Delhi 110010, India (e-mail: manish_dwl@yahoo.com).
}

\begin{abstract}
Burst fractures of dorsolumbar vertebrae are a common occurrence. There is presence of dural tear in approximately $7.7 \%$ of cases, but its diagnosis is commonly missed because of lack of preoperative suspicion. Its preoperative diagnosis is an important adjunct in making a rationale decision for choosing surgical approaches and care during surgery. Magnetic resonance imaging (MRI) is not always helpful in its

Keywords

- dorsolumbar vertebrae

- burst fractures

- dural tear

- interpedicular distance

- canal compromise

- laminar fracture detection and has its own drawbacks. Out of a total of 27 patients operated for burst fractures of dorsolumbar vertebrae, 3 had a dural tear. Patients who were suspected to have dural tears were taken up for surgical intervention either only posteriorly or along with anterior approach. All three patients had neurologic deficits, widened interpedicular distance, laminar fracture of Gd 1 or more with canal compromise greater than $50 \%$, and wedging with an acute angle. Presence of dural tear with wedging of roots was confirmed intraoperatively. Active effort should be made to detect presence of dural tears if patients of dorsolumbar burst fractures have neurologic deficit, laminar fracture is present, interpedicular distance is widened, and there is severe canal encroachment with an acute angle of the wedge.
\end{abstract}

\section{Introduction}

Burst fractures of the dorsolumbar vertebrae are defined as fractures of at least the anterior and middle columns of the vertebrae occurring as a result of axial compression with some amount of flexion. ${ }^{1}$ In approximately $7.7 \%$ of cases undergoing surgery, there is an associated dural tear. ${ }^{2} \mathrm{~A}$ preoperative diagnosis of associated dural tear is an important adjunct in rationale for optimal management. ${ }^{3}$

Preoperative diagnosis of dural tear by magnetic resonance imaging (MRI) is difficult, especially if tears are smaller than $1 \mathrm{~cm} .{ }^{4}$ Myelography, although a better diagnostic procedure, may not be tolerated by the patient and is also an invasive procedure. ${ }^{5}$ Evaluation of X-rays, computed tomographic (CT) scan, and MRI of patients with burst fractures provides us with adequate inputs leading to higher suspicion and detection of presence of dural tears.

In the present article we discuss three cases with burst

received

April 8, 2015

accepted after revision

April 4, 2016

published online

March 6, 2017
DOI http://dx.doi.org/

10.1055/s-0036-1584599. ISSN 2277-954X. fractures of lumber vertebrae that were suspected to have dural tears based on the available radiology. It was confirmed intraoperatively leading to a better management of patients.

\section{Materials and Methods}

A total of 27 cases of burst fractures were operated during a 3-year period ( - Table $\mathbf{1}$ ). Incidental detection of a dural tear triggered a literature review and attempt to preoperatively diagnose presence of dural tear. Patients with dorsolumbar fractures requiring surgical intervention were evaluated with X-ray, CT, and MRI scans. They were evaluated for five parameters.

1. Interpedicular distance: Distance in millimeter between the inner surfaces of the pedicles as seen on anteroposterior views of X-ray ( $\mathbf{- F i g} \mathbf{1}$ ).

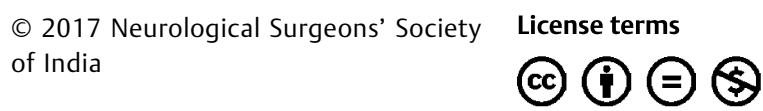


Table 1 Spectrum of vertebral fractures

\begin{tabular}{|l|l|}
\hline Fractured vertebra & Number of cases \\
\hline D5 & 1 \\
\hline D6 & 3 \\
\hline D8 & 2 \\
\hline D9 & 1 \\
\hline D11 & 4 \\
\hline D12 & $3^{*}$ \\
\hline L1 & $5^{*}$ \\
\hline L2 & 7 \\
\hline L3 & 1 \\
\hline L4 & 1 \\
\hline Total & $\begin{array}{l}28^{*} \text { (One case had } \\
\text { two vertebral fractures } \\
\text { simultaneously) }\end{array}$ \\
\hline
\end{tabular}

2. Angle of retropulsed segment: Most acute angle produced by two lines along the superior and inferior surfaces of wedged fracture segment as seen on the sagittal MRI (-Fig 2).

3. Canal compromise: Percentage of the canal compromise by the wedged fracture segment ( - Fig 3 ).

4. Presence of laminar fracture (-Fig 3 ).

5. Degree of laminar fracture

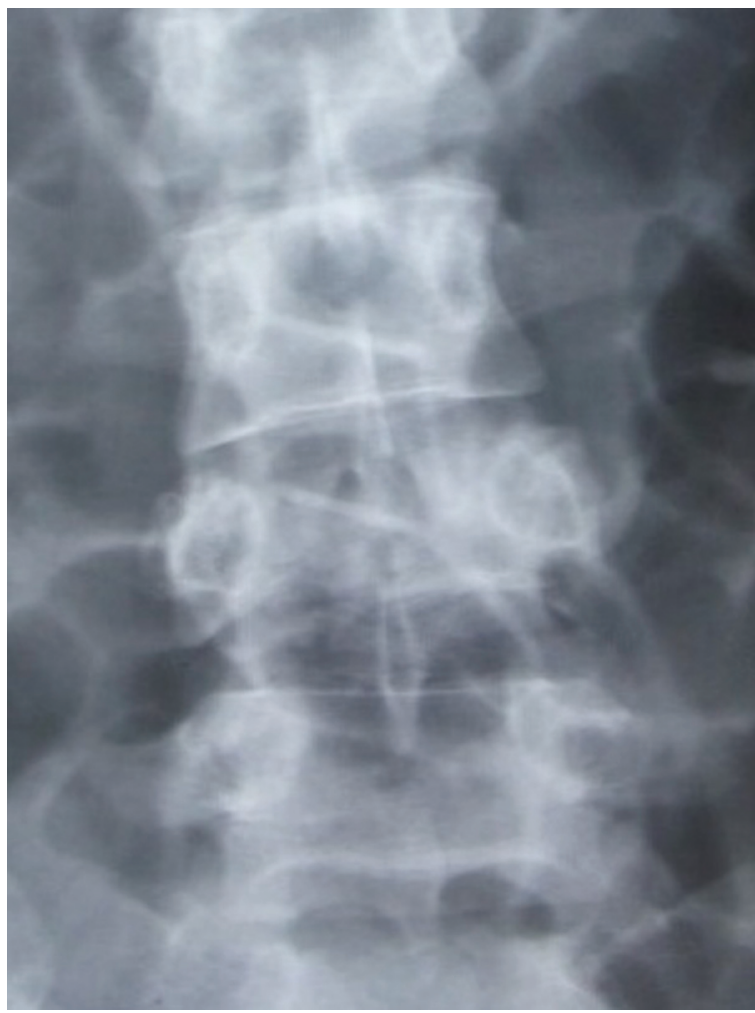

Fig. 1 X-ray AP view showing widening of the interpedicular distance.
Laminar fractures were graded as under

Grade 0: no fracture

Grade 1: fracture without a gap

Grade 2: fracture with gap

Grade 3: displaced fracture

On the basis of these parameters, dural tear was suspected in five cases. Out of these five, three were confirmed to have dural tears intraoperatively. None of the 22 cases that were radiologically not suspected to have dural tears had any intraoperative evidence of dural tear or cerebrospinal fluid (CSF) leakage (-Table $\mathbf{2}$ ).

On suspicion of presence of dural tear, deliberate surgical plan to include posterior approach was made and intraoperatively tear was confirmed and repaired (-Fig 4, -Table 3). Every effort was taken to salvage anatomical continuity of nerve roots. Patients were followed in the postoperative period for neurologic recovery.

\section{Case 1}

A 45-year-old man sustained a burst fracture of lumbar vertebra 2 (L2) after a fall from a height of approximately 10 $\mathrm{ft}$. Detailed neurologic examination was done ( - Table 4 ).

The patient was taken for decompression and stabilization on third postinjury day. As a first step the

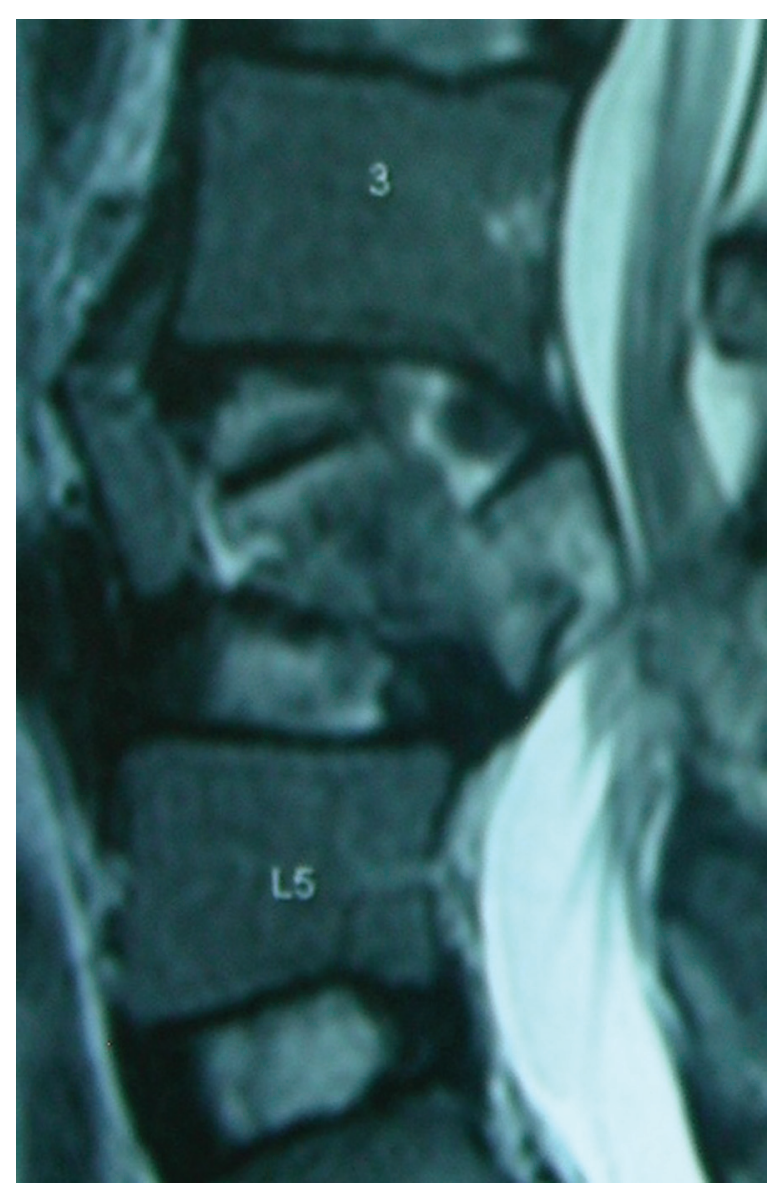

Fig. 2 Sagittal MRI showing acute angle of retropulsed segment. 


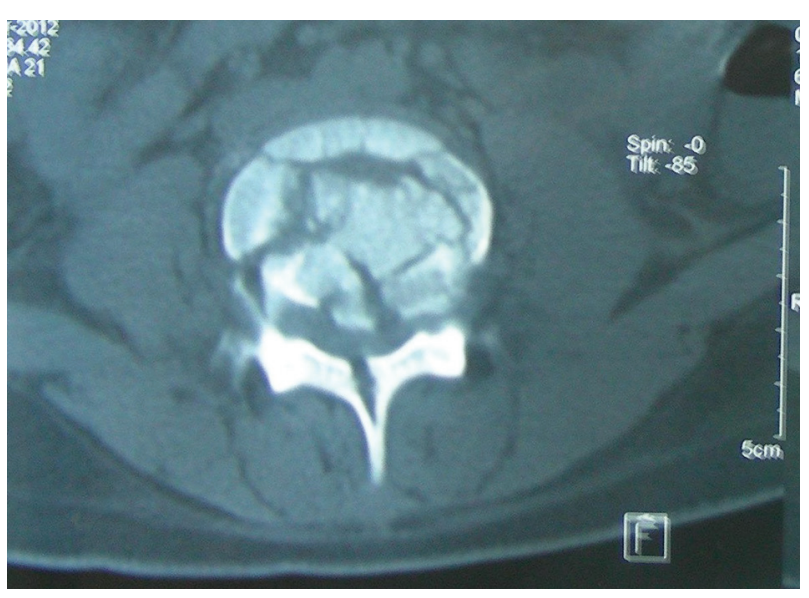

Fig. 3 NCCT axial section showing canal compromise and fractured lamina.

patient was approached anterolaterally, corpectomy L2 was done, and expandable cage was placed. The patient was thereafter turned prone and posterior approach was taken. Fracture of the spinous process and lamina was confirmed and laminectomy done taking due precautions to avoid injury to avulsed nerve roots. The dura was found torn and the nerve roots had avulsed. The nerve roots were found to be wedged inside the fracture of spinous process and were released. The nerve roots were repositioned and the dura closed primarily. The patient was followed up closely and over a period of 3 months, and he showed steady improvement (-Table 4).

\section{Case 2}

A young 20-year-old girl had a fall from a height of approximately 12 to $14 \mathrm{ft}$ and had pain while moving her lower limbs. The patient was unable to void. Detailed neurologic examination ( - Table 4 ) and assessment of

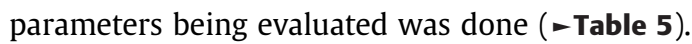

The patient had been previously managed conservatively at a peripheral hospital for approximately 14 days. On reporting to our center and evaluation of radiologic parameters as discussed, there was a strong suspicion of dural tear along with the burst fracture. She was taken up for emergency surgery on the second post admission day. A posterior approach was taken. Due care was taken intraoperatively while doing laminectomy so that any retropulsed roots do not get damaged inadvertently. A 2$\mathrm{cm}$ dural tear with herniated roots was confirmed. Roots were carefully separated from the impinging bony chips of spinous process and lamina, repositioned, and duraplasty

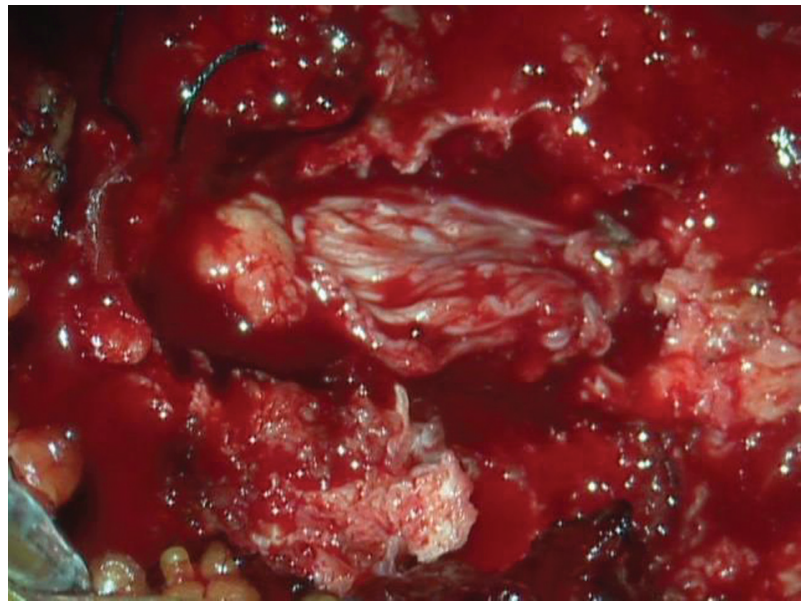

Fig. 4 Intraoperative image showing dural tear and exposed nerve roots.

was done. The patient, however, did not show any improvement in her bladder functions even at the end of 12 weeks of observation, possibly because of the delay in diagnosis.

\section{Case 3}

A 45-year-old man was hospitalized after a fall from a height of approximately $15 \mathrm{ft}$. He had weakness of the both lower limbs. The patient had to be catheterized as he was unable to void and had distended urinary bladder. Detailed neurologic examination ( - Table 4 ) and assessment of parameters being evaluated was done ( $\mathbf{- T a b l e ~} \mathbf{5}$ ).

Initially an anterolateral approach was taken and corpectomy of L1 was done with placement of expandable cage. Thereafter the patient was turned prone and laminectomy performed with due care. A $1.5-\mathrm{cm}$-long dural tear with prolapsed nerve roots was visualized. Due precautions were taken and nerve roots repositioned after separating from bony spicules. Pedicle screw fixation was done. The patient had a steady recovery, and by the end of 12 weeks he had only deficit in the form of grade $4 / 5$ power in the (Lt) lower limb.

\section{Discussion}

The literature is replete with discussions of fractures occurring at various segments of spinal cord. Role of plane of facets has been described in the occurrence of a particular type of impacted fracture. ${ }^{3}$ Facets at the midlumbar region are in sagittal plane. A vertical impaction force leads to hyperextension at midlumbar level that leads to impaction

Table 2 Correlation of radiologic suspicion and intraoperative findings

\begin{tabular}{|l|l|l|l|}
\hline & Dural tear present & Dural tear not present & Total \\
\hline Dural tear suspected & 3 & 2 & 5 \\
\hline Dural tear not suspected & 0 & 22 & 22 \\
\hline Total & 3 & 24 & 27 \\
\hline
\end{tabular}


Table 3 Surgical procedures performed and intraoperative findings

\begin{tabular}{|c|c|c|c|c|}
\hline Operation details & & Case 1 & Case 2 & Case 3 \\
\hline \multirow{2}{*}{$\begin{array}{l}\text { Intraoperative } \\
\text { findings }\end{array}$} & Dura & Torn & Torn & Torn \\
\hline & Nerve roots & Prolapsed & Prolapsed & Prolapsed \\
\hline \multirow[t]{2}{*}{ Surgery } & Approach & $\begin{array}{l}\text { Anterolateral + } \\
\text { posterior }\end{array}$ & Posterior approach. & Anterolateral + posterior \\
\hline & Procedure & $\begin{array}{l}\text { Corpectomy L2 }+ \\
\text { expandable cage } \\
\text { Dural repair and } \\
\text { pedicular screw fixation }\end{array}$ & $\begin{array}{l}\text { Transpedicular } \\
\text { decompression } \\
\text { Dural repair and } \\
\text { pedicular screw fixation }\end{array}$ & $\begin{array}{l}\text { Corpectomy LV1 and } \\
\text { expandable cage placement } \\
\text { Dural repair pedicular } \\
\text { screw fixation }\end{array}$ \\
\hline
\end{tabular}

Table 4 Periodic follow-up status of patients up to 12 weeks

\begin{tabular}{|c|c|c|c|c|c|c|c|c|c|c|c|c|c|c|}
\hline \multicolumn{3}{|c|}{ Post-op recovery } & \multicolumn{4}{|l|}{ Case 1} & \multicolumn{4}{|l|}{ Case 2} & \multicolumn{4}{|l|}{ Case 3} \\
\hline & & & Pre-op & $2 \mathrm{wk}$ & $4 \mathrm{wk}$ & $12 \mathrm{wk}$ & Pre-op & $2 \mathrm{wk}$ & $4 \mathrm{wk}$ & $12 \mathrm{wk}$ & Pre-op & $2 \mathrm{wk}$ & $4 \mathrm{wk}$ & $12 \mathrm{wk}$ \\
\hline \multirow[t]{6}{*}{ Motor } & \multirow[t]{2}{*}{ Hip } & (Rt) & $2 / 5$ & $4 / 5$ & $4+15$ & $5 / 5$ & $5 / 5$ & $5 / 5$ & $5 / 5$ & $5 / 5$ & $3 / 5$ & $4 / 5$ & $5 / 5$ & $5 / 5$ \\
\hline & & $(\mathrm{Lt})$ & $1 / 5$ & $3 / 5$ & $4 / 5$ & $4+15$ & $4 / 5$ & $4 / 5$ & $4 / 5$ & $4+/ 5$ & $1 / 5$ & $3 / 5$ & $4 / 5$ & $4 / 5$ \\
\hline & \multirow[t]{2}{*}{ Knee } & (Rt) & $2 / 5$ & $4 / 5$ & $4+15$ & $5 / 5$ & $4+15$ & $4+15$ & $5 / 5$ & $5 / 5$ & $2 / 5$ & $4 / 5$ & $4 / 5$ & $4 / 5$ \\
\hline & & $(\mathrm{Lt})$ & $1 / 5$ & $3 / 5$ & $4 / 5$ & $5 / 5$ & $4+15$ & $4+15$ & $5 / 5$ & $5 / 5$ & $1 / 5$ & $3 / 5$ & $4 / 5$ & $4 / 5$ \\
\hline & \multirow[t]{2}{*}{ Ankle } & (Rt) & $2 / 5$ & $4 / 5$ & $4+15$ & $5 / 5$ & $2 / 5$ & $4 / 5$ & $4 / 5$ & $4 / 5$ & $2 / 5$ & $4 / 5$ & $4+15$ & $5 / 5$ \\
\hline & & (Lt) & $1 / 5$ & $3 / 5$ & $4 / 5$ & $5 / 5$ & $3 / 5$ & $4 / 5$ & $4 / 5$ & $4 / 5$ & $1 / 5$ & $3 / 5$ & $4+15$ & $5 / 5$ \\
\hline \multicolumn{3}{|c|}{ Perianal sensory loss } & $10 \%$ & $50 \%$ & Normal & Normal & + & + & + & + & $40 \%$ & $50 \%$ & $50 \%$ & Normal \\
\hline \multicolumn{3}{|c|}{ Bladder control } & $\begin{array}{l}\text { On } \\
\text { catheter }\end{array}$ & On SCIC & $\begin{array}{l}\text { Self- } \\
\text { voiding }\end{array}$ & $\begin{array}{l}\text { Self- } \\
\text { voiding }\end{array}$ & $\begin{array}{l}\text { On } \\
\text { catheter }\end{array}$ & $\begin{array}{l}\text { On } \\
\text { SCIC }\end{array}$ & $\begin{array}{l}\text { On } \\
\text { SCIC }\end{array}$ & $\begin{array}{l}\text { On } \\
\text { SCIC }\end{array}$ & $\begin{array}{l}\text { On } \\
\text { catheter }\end{array}$ & $\mathrm{SCIC}$ & $\mathrm{SCIC}$ & Self-voiding \\
\hline
\end{tabular}

Abbreviations: Lt, left; post-op, postoperative; pre-op, preoperative; Rt, right; SCIC, self clean intermittent catheterization.

Table 5 Radiologic parameters used to suspect dural tear

\begin{tabular}{|c|c|c|c|c|c|c|}
\hline Radiologic parameters & \multicolumn{2}{|l|}{ Case 1} & \multicolumn{2}{|l|}{ Case 2} & \multicolumn{2}{|l|}{ Case 3} \\
\hline Interpedicular distance & L1 (higher) & $25 \mathrm{~mm}$ & L3 (higher) & $19 \mathrm{~mm}$ & D12 (higher) & $23 \mathrm{~mm}$ \\
\hline & L2 (fractured) & $34 \mathrm{~mm}$ & L4 (fractured) & $27 \mathrm{~mm}$ & L1 (fractured) & $31 \mathrm{~mm}$ \\
\hline & L3 (lower) & $29 \mathrm{~mm}$ & L5 (lower) & $21 \mathrm{~mm}$ & L2 (lower) & $26 \mathrm{~mm}$ \\
\hline Angle of retropulsed segment & \multicolumn{2}{|l|}{$120^{\circ}$} & \multicolumn{2}{|l|}{$130^{\circ}$} & \multicolumn{2}{|l|}{$130^{\circ}$} \\
\hline Canal compromise & \multicolumn{2}{|l|}{$80 \%$} & \multicolumn{2}{|l|}{$70 \%$} & \multicolumn{2}{|l|}{$80 \%$} \\
\hline Laminar fracture & \multicolumn{2}{|l|}{ Present } & \multicolumn{2}{|l|}{ Present } & \multicolumn{2}{|l|}{ Present } \\
\hline Degree of laminar fracture & \multicolumn{2}{|l|}{$\|$} & \multicolumn{2}{|l|}{$\|$} & \multicolumn{2}{|l|}{$\|$} \\
\hline
\end{tabular}

of a wedge of inferior articular process into the pars interarticularis of the next vertebra below. This leads to apophyseal joint-pedicle-body complex being pushed laterally. This has been hypothesized to produce a vertical tear in the theca as a result of lateral traction on the nerve roots. ${ }^{3}$ This leads to the characteristic dural tear and entrapment of nerve roots in the fractured posterior segments.

Patients with neurologic deficits and a laminar fracture associated with a burst fracture of lumbar vertebra have an increased risk of dural lacerations and possibilities of entrapment of neural elements. Burst fracture with an associated laminar fracture has been found to be $100 \%$ sensitive and $74 \%$ specific for presence of dural tear. ${ }^{3} \mathrm{~A}$ higher degree of laminar fracture is associated with higher rate of dural fracture. Posterior dural lacerations are always associated with laminar fractures and are caused by posteriorly displaced dural sac being impaled on sharp edge of laminar fracture. ${ }^{6}$ Narrowing of central canal to less than one-half compared with normal cross-sectional diameter has been highly associated with dural tear. ${ }^{7}$

MRI does not directly reveal the presence of dural tear although CSF accumulations and pseudomeningocele may be visualized. Contrast myelography, although more advantageous, is now obsolete as it lacks cross-sectional features and anatomical superimposition. In addition, 
14 Dural Tears Associated with Burst Fractures of Lumbar Vertebrae Sharma et al.

patient manipulation is required during the procedure, which can produce or aggravate neurologic deficits.

Preoperative knowledge of actual presence of dural tear in patient with spinal fractures is an important adjunct to the rationale for optimal management. If a dural tear is suspected, extra effort can be made intraoperatively to identify dural tear.

\section{Conclusion}

Preoperative knowledge or high suspicion of presence of dural tear is an important adjunct relating to optimal management and can be strongly suspected in presence of undermentioned factors:

1. Interpedicular distance: Wider interpedicular distance as compared with that of upper and lower vertebrae.

2. Angle of retropulsed segment less than 135 degrees

3. Canal compromise greater than $50 \%$

4. Laminar fracture: Presence

5. Degree of laminar fracture greater than Gd 1.

\section{Author Contribution}

M.S. contributed to the concept and design of the study and was instrumental in collection of data, their analysis, and interpretation. He also drafted the final manuscript. A.K.S. was instrumental in manuscript editing, critical revision, and final approval. M.G. was instrumental in manuscript editing and critical revision. G.K. contributed by data acquisition and to manuscript writing.

Note

The article was presented as a poster at NSSI 2014 meet.

\section{References}

1 Denis F. The three column spine and its significance in the classification of acute thoracolumbar spinal injuries. Spine 1983; 8(8):817-831

2 Keenen TL, Antony J, Benson DR. Dural tears associated with lumbar burst fractures. J Orthop Trauma 1990;4(3):243-245

3 Miller CA, Dewey RC, Hunt WE. Impaction fracture of the lumbar vertebrae with dural tear. J Neurosurg 1980;53(6):765-771

4 Jensen MC, Kelly AP, Brant-Zawadzki MN. MRI of degenerative disease of the lumbar spine. Magn Reson Q 1994;10(3):173-190

5 Morris RE, Hasso AN, Thompson JR, Hinshaw DB Jr, Vu LH. Traumatic dural tears: CT diagnosis using metrizamide. Radiology 1984;152(2):443-446

6 Pickett J, Blumenkopf B. Dural lacerations and thoracolumbar fractures. J Spinal Disord 1989;2(2):99-103

7 Silvestro C, Francaviglia N, Bragazzi R, Piatelli G, Viale GL. On the predictive value of radiological signs for the presence of dural lacerations related to fractures of the lower thoracic or lumbar spine. J Spinal Disord 1991;4(1):49-53 